\title{
Religion as a Social Determinant of Public Health, By Ellen Idler, Ed, Oxford University Press, 2014
}

\author{
Stephen C. Ko ${ }^{\mathrm{a}}$ \\ ${ }^{a}$ MD, MA, MPH, MDiv, Assistant Professor of Global Health, Boston University School of Public Health, \\ USA.
}

The overall assertion of this unique work lies squarely in its title, Religion as a Social Determinant of Public Health. As the prevailing research and policy model utilized in public health, the social determinants perspective presupposes that primary determinants of health are not necessarily clinical care and the provision of services, but rather the circumstances and conditions affecting daily living. The authors contend that religion should not only be considered as an independent determinant of health, but also for its various interactions with other influential determinants such as politics and economics.

In 2005, Emory University began a strategic initiative on religion and human spirit, resulting in the formation of the Religion and Public Health Collaborative. The origins of this book stem from this initial collaborative and subsequent interdisciplinary faculty seminar from 2010-2013. During this time, predominantly Emory faculty from a diverse set of scientific, scholarly, and professional backgrounds developed the outlines, manuscripts, and eventual chapters of the volume.

Divided into five parts, the first reports on religious practices within major faith traditions worldwide. Categorized by their cycles of repetition, scholars portray time-honored practices contextualized within their religious frames. Daily practices of vegetarianism in Seventh Day Adventists and refuge meditation in Contemporary Buddhism are presented alongside weekly practices celebrating Eucharist in Roman Catholicism. Annual religious practices such as fasting in Islam are described alongside one-time religious practices of circumcision in Judaism and baptism among
Latin American Pentecostals. These depictions provide the groundwork for analysis of associations between religion and public health.

The second part traces the impact of religion on public health in the last two centuries, exclusively within the United States and England. Major movements are assessed, the first being John Wesley's impact on public health through the Methodist Church. There, a fundamental burden for the poor led to increased access to healthcare and enhancement of layman medical training through the publication Primitive Physick. Within the United States, the Social Gospel movement's positive impact on public health is juxtaposed to the deleterious effects of $19^{\text {th }}$ century Comstock Laws on reproductive health.

In the third part, authors investigate current research involving religion as a social determinant of individual physical and mental health along a life course perspective. From religious beliefs and their impact on maternal and child health to rituals and the comfort they provide to geriatric patients coping with end of life issues, empiric evidence is deconstructed and examined. Meanwhile, the natural intersection between religious practices and mental health is considered, focusing on the impact of ethical values and moral emotions.

In the fourth part of the book, the effect of religious institutions on global health is reviewed in the context of low and middle income countries. Highlights include a historical narrative of the complex relationship between neighboring World Council of Churches and World Health Organization. Initial collaborative programs between the two institu- 
tions are uncovered while tracing the evolution of hospital-based tertiary care to an emphasis on primary care reaching individual communities. This Christian Medical Commission focus ultimately led to WHO's momentous Alma-Ata Declaration on Primary Care in 1978. The history of several prominent religious organizations are espoused, including the African Religious Health Assets Programme (ARHAP) with its pioneering focus on identifying and understanding the role of religious assets for health. Other highlighted religious institutions include the La Leche League, Heifer International, Shri Kshetra Dharmasthala Rural Development Program, Khaka Ahsania Mission, and L'Arche Community.

Finally, the role of religion and religious institutions is scrutinized during three principal public health challenges in recent history. These include HIV/AIDS, influenza, and Alzheimer's disease. Each is unique in its epidemiology, pathophysiology, morbidity, and mortality. Yet, each possesses epidemic potential beyond geopolitical borders. In particular, the complex role of religious institutions within the history of the HIV/AIDS crisis is conveyed. This includes positive impacts such as the creation of the AIDS National Interfaith Network along with more nuanced tensions resulting from religious beliefs that HIV virus is a punishment from God, the consequence of immoral behavior, or the result of karma.

|

Competing Interests: None declared. Dr. Ko is on the Editorial Board of CJGH

Correspondence: Professor Stephen C Ko. 801 Massachusetts Avenue, $3^{\text {rd }}$ Floor, Boston, MA 02118. USA. scko@bu.edu

Cite this article as: Ko, S. Book review: Religion as a social determinant of public health, by Ellen Idler, Oxford University Press, 2014. Christian Journal for Global Health (Nov 2015), 2(2): 76-77.

(C) Ko, S. This is an open-access article distributed under the terms of the Creative Commons Attribution License, which permits unrestricted use, distribution, and reproduction in any medium, provided the original author and source are properly cited. To view a copy of the license, visit http://creativecommons.org/licenses/by/3.0/

www.cjgh.org

Nov 2015. Christian Journal for Global Health 2(2): 76-77.
The authors have built a compelling argument supporting the addition of religion as a significant determinant of public health. They have done this by investigating the complex effects of religion and religious institutions on public health in various contexts throughout history. The book's unique interdisciplinary approach yields different perspectives into the complexity of this topic while affirming the need for broader conversation and dialogue. In July 2015, the Lancet published a series on "faith-based healthcare" arguing that the extensive experiences, strengths, and capacities opportunity to improve health outcomes. For Christians, the paradigm of holistic ministry encompassing physical and spiritual healing dates back to Levitical laws within the Pentateuch and the earthly ministry of Christ. Not surprisingly, Christian ideology and Christian institutions have had a major impact on public health for some time. However, these roles have largely been overlooked, discounted, and ignored. With burgeoning awareness and momentum, the essays within this book lay the foundation for inclusion of religion, religious beliefs, and religious institutions as social determinants of public health. In doing so, they reinforce the incorporation of Christian beliefs, practice, and theology within the framework of public health participation and research. For it is precisely these underlying principles of charity, compassion, and selfsacrificial love that lie at the heart of influential Christian engagement. of faith-based organizations offer a unique

http://crea 